\title{
Characterization of resveratrol content in ten wild species of section Arachis, genus Arachis
}

\author{
Renata Miranda Lopes • Dâmaris Silveira • Marcos Aparecido Gimenes • \\ Paula Andreia S. Vasconcelos • Rosa de Belem N. Alves · Joseane Padilha Silva • \\ Tânia da Silveira Agostini-Costa
}

Received: 18 September 2012/Accepted: 11 March 2013/Published online: 11 April 2013

(C) Springer Science+Business Media Dordrecht 2013

\begin{abstract}
Peanut is one of the few plants that synthesizes resveratrol, a phenolic compound of the stilbene class, which has been associated with reduced risk of developing chronic diseases, such as cancer, cardiovascular diseases, skin diseases, pulmonary diseases, diabetes and neurological diseases. Resveratrol was detected in different parts of the peanut plant, including roots, leaves, seeds and their derivatives. The wild species of the Arachis section are also strong candidates to synthesize resveratrol because they are phylogenetically closely related to cultivated peanut. Our objective was to characterize the resveratrol content in ten wild species of Arachis with three different genomes (A, B and $\mathrm{K}$ ). The plant material was composed of leaves of the ten species treated (test) and not treated (control) with ultraviolet (UV)
\end{abstract}

R. M. Lopes · D. Silveira

College of Health Sciences, University of Brasília, Campus Darcy Ribeiro, Asa Norte, Brasília,

DF 70910-900, Brazil

R. M. Lopes - M. A. Gimenes - P. A. S. Vasconcelos R. B. N. Alves - J. P. Silva - T. S. Agostini-Costa ( $\square)$ Embrapa Genetic Resources and Biotechnology, Parque Estação Biológica PqEB, Av. W5 Norte final, Brasília, DF 702372, Brazil

e-mail: tania.costa@embrapa.br

M. A. Gimenes · P. A. S. Vasconcelos Institute of Biosciences, University Estadual Paulista, Júlio de Mesquita Filho, Distrito de Rubião Júnior, Botucatu, SP, Brazil radiation. The test and control samples were extracted and the identification and quantification of resveratrol was performed using high performance liquid chromatography (HPLC). All species studied synthesized resveratrol and the concentrations ranged from $299.5 \mu \mathrm{g} / \mathrm{g}$ in A. kempff-mercadoi to $819.9 \mu \mathrm{g} / \mathrm{g}$ in A. cardenasii. DPPH antioxidant activity varied between $18.7 \%$ for A. duranensis and $48.2 \%$ in A. simpsonii. The results showed that wild Arachis species are a potential source of alleles for improvement of cultivated peanut, with the aim of achieving higher resveratrol content in leaves.

Keywords Antioxidant - Fabaceae - Peanut · Stilbene · Wild Arachis

\section{Introduction}

Peanut is one of the few plants that synthesize resveratrol (3, 5, 4'-trihidroxistilbene), a phenolic compound of the stilbene class. This bioactive compound has been associated with reduced risk of developing several chronic diseases, such as cancer, cardiovascular diseases, skin diseases, pulmonary diseases, diabetes and neurological diseases (Harikumar and Aggarwal 2008; Fulda 2010; Lopes et al. 2011).

Sobolev and Cole (1999) found resveratrol content between 0.0 and $0.1 \mu \mathrm{g} / \mathrm{g}$ in products derived from roasted peanut, $0.1-0.5 \mu \mathrm{g} / \mathrm{g}$ in peanut butter, and $0.0-7.9 \mu \mathrm{g} / \mathrm{g}$ in boiled peanuts. Resveratrol was also 
detected in the hypocotyls in response to fungal infection (Ingham 1976), in cotyledons in response to mechanical injury (Arora and Strange 1991), in stalks in response to ultraviolet $\mathrm{C}$ light or biotic stress (Fritzemeier et al. 1983; Yang et al. 2010), in leaves under biotic and abiotic stresses (Chung et al. 2003), in non-stressed seeds $(0.0-2.0 \mu \mathrm{g} / \mathrm{g}$ ) (Sanders et al. 2000; Tokusoglu et al. 2005; Chukwumah et al. 2012), in UV stressed seeds (2.1-4.7 $\mu \mathrm{g} / \mathrm{g})$ (Potrebko and Resurreccion 2009) and in roots $(0.027-0.950 \mathrm{mg} / \mathrm{g}$ ) (Chen et al. 2002).

Alternative means to increase the resveratrol content in peanut are the identification of accessions with high levels of this substance, which previous studies demonstrate to be unlikely; the use of transgenic plants, which has not been accepted by consumers, and the identification of wild species of Arachis with high levels of resveratrol that can be used in peanut breeding programs.

No study on resveratrol in wild species of Arachis has been reported. However, wild Arachis species of Arachis section are strong candidates to synthesize resveratrol, since they are phylogenetically closely to peanut (Cunha et al. 2008; Bechara et al. 2010). Phylogenetic and chemotaxonomic information has proven to be useful in identifying species that produce compounds from well defined chemical classes and pharmacological activities (Brito 1996; Rates 2001), such as resveratrol.

The section Arachis, one of nine taxonomic sections of the genus Arachis, comprises A. hypogaea and 31 wild species that are very closely related to the cultivated peanut, which is an allotetraploid that originated from a spontaneous cross between two diploid species of A and B genomes (Valls and Simpson 2005; Favero et al. 2006; Krapovickas and Gregory 2007; Cunha et al. 2008; Bechara et al. 2010). According to the evidence, Arachis duranensis and A. ipaënsis are the donors of the genomes A and B respectively (Favero et al. 2006; Grabiele et al. 2012).

The characterization and evaluation studies on wild Arachis species have been accompanied by the development of map populations (Moretzsohn et al. 2005; Moretzsohn et al. 2009), synthetic allopolyploids by crossing between A and B wild species (Mallikarjuna et al. 2011; Nielen et al. 2012) and introgression lines resulting from crosses between allopolyploids and A. hypogaea.

The objective of this study was to evaluate the resveratrol level by HPLC in leaves of ten wild species of Arachis (A. batizocoi, A. cardenasii, A. cruziana, A. duranensis, A. gregoryii, A. ipaënsis, A. kempffmercadoi, A. kuhlmannii, A. magna, and A. simpsonii) with four different genomes (A, B, AB and $\mathrm{K}$ ) before and after exposure to UV light. In addition, the leaf extracts were evaluated for their inhibitory activity against the DPPH free radical.

\section{Experimental}

General experimental procedures

Stock solutions of trans-resveratrol (99\%, SigmaAldrich, St. Louis, MO, USA) were prepared at 230-460 $\mu \mathrm{g} / \mathrm{mL}$ and phenolphthalein (98 \% SigmaAldrich, St. Louis, MO, USA) at 507.4-5,854.0 $\mu \mathrm{g} / \mathrm{mL}$ in absolute ethanol and stored at $-20{ }^{\circ} \mathrm{C}$ for up to 3 months in the absence of oxygen and under protection from light. The 2, 2-diphenyl-1-picrylhydrazyl was obtained from Sigma-Aldrich (St. Louis, MO, USA). Acetonitrile (grade HPLC) and phosphoric acid (86 \%) were obtained from J. T. Baker (Phillipsburg, NJ, USA), hexane from Merck (Darmstadt, HE, Germany) and absolute ethanol from Vetec (Rio de Janeiro, RJ, Brazil). HPLC analysis was carried out on a ProStar Varian ${ }^{\circledR}$ system (Mulgrave, VIC, Australia) equipped with ternary pump, autosampler and photodiode array detector (PDA PS-240/PS-410/ Galaxie PS-335/Software 1.9). The column used was C18 Zorbax XDB Agilent ${ }^{\circledR}(250 \times 4.6 \mathrm{~mm}, 5 \mathrm{~mm})$ (Agilent ${ }^{\circledR}$ Technologies, Santa Clara, CA, USA).

\section{Plant material}

Seeds of A. hypogaea and ten wild species from the active germoplasm bank of Arachis (Table 1) were grown in three experimental blocks in the greenhouse at Embrapa Recursos Genéticos e Biotecnologia (Brasília, Brazil) in October 2010. The cultivated peanut, A. hypogaea, was used in this experiment as a reference species.

Resveratrol induction

Leaves of each accession were collected between February and March of 2011 in the afternoon using scissors and randomly divided into two sub-samples (control-no treatment with UV; test-treated with 
Table 1 Arachis species evaluated for resveratrol content, types of genomes of each species and accession number

\begin{tabular}{|c|c|c|}
\hline Species & Genome & Access \\
\hline A. batizocoi Krapov. et W. C. Greg. & $\mathrm{K}$ & K 9484 \\
\hline $\begin{array}{l}\text { A. cardenasii Krapov. et } \\
\text { W. C. Greg. }\end{array}$ & A & GKP 10017 \\
\hline $\begin{array}{l}\text { A. cruziana Krapov., W. C. Greg. et } \\
\text { C. E. Simpson }\end{array}$ & $\mathrm{K}$ & WI 1302-3 \\
\hline $\begin{array}{l}\text { A. duranensis Krapov. et } \\
\text { W. C. Greg. }\end{array}$ & A & K 7988 \\
\hline $\begin{array}{l}\text { A. gregoryii C. E. Simpson, } \\
\text { Krapov. et Valls }\end{array}$ & A & V 6389 \\
\hline A. ipaënsis Krapov. et W. C. Greg. & $\mathrm{B}$ & KG 30076 \\
\hline $\begin{array}{l}\text { A. kempff-mercadoi Krapov., } \\
\text { W. C. Greg. et C. E.Simpson }\end{array}$ & A & V 13250 \\
\hline $\begin{array}{l}\text { A. kuhlmannii Krapov. et } \\
\text { W. C. Greg. }\end{array}$ & A & V 9214 \\
\hline $\begin{array}{l}\text { A. magna Krapov., W. C. Greg. et } \\
\text { C. E. Simpson }\end{array}$ & $\mathrm{B}$ & KG 30097 \\
\hline $\begin{array}{l}\text { A. simpsonii Krapov. et } \\
\text { W. C. Greg. }\end{array}$ & $\mathrm{B}$ & V 13710 \\
\hline A. hypogaea Linnaeus & $\mathrm{AB}$ & Cv Caiapó \\
\hline
\end{tabular}

UV). Resveratrol induction in leaves of wild Arachis was done according to methodology previously described for seeds and leaves of A. hypogaea (Potrebko and Resurreccion 2009; Chung et al. 2003). Briefly, leaves of each sub-sample were placed in trays $(45 \mathrm{~cm} \times 30 \mathrm{~cm})$, which contained a layer of germitest paper under a layer of approximately $1 \mathrm{~cm}$ of cotton moistened with $200 \mathrm{ml}$ of water. The tray with test samples was placed in a laminar flow chamber (Trox ${ }^{\circledR}$-Curitiba, PR, Brazil-Model FLV series: 235-81) with UV lamps (Philips ${ }^{\circledR}$ —São Paulo, SP, Brazil-TUV $30 \mathrm{~W} / \mathrm{G} 30$ T8 Longlife) for $2 \mathrm{~h}$ and $30 \mathrm{~min}$. The tray of the control sample was maintained at room temperature and under white light for the same time as the test sample. After treatment, both samples remained in the dark for $15 \mathrm{~h}$. Later, the leaflets were detached from the petiole and homogenized within each subgroup. One gram of leaflets was weighed in Falcon tubes, protected with aluminum foil. The samples were frozen at $-80{ }^{\circ} \mathrm{C}$, for 5-20 days, until extraction of resveratrol.

Resveratrol analysis

The procedure of extracting resveratrol was carried out with light protection according to Potrebko and
Resurreccion (2009), with some changes. Maceration of the leaflets was performed in liquid nitrogen by pulverizing with a glass rod directly in the tube. Ten $\mathrm{mL}$ of $\mathrm{EtOH} 80 \%$ was added to the pulverized material, and extraction was performed in a Polytron homogenizer (Kinematica ${ }^{\circledR}$, Lucerne, LU, Switzerland) for $2 \mathrm{~min}$ at 20,000 rpm. After extraction, the stem of the homogenizer was washed with $2 \mathrm{ml}$ of EtOH $80 \%$ to ensure complete recovery of the extracted material. Two $\mathrm{ml}$ of the supernatant of the ethanol extract were mixed to $2 \mathrm{~mL}$ of hexane in $4 \mathrm{~mL}$ vials. The vial was agitated manually and carefully for the two phases to be mixed efficiently. The vial was left to sit for approximately $1 \mathrm{~min}$ to separate the two phases. The upper phase, which was intense green due to the presence of chlorophyll, was separated carefully with a Pasteur pipette and discarded. The process of defatting was repeated and the solvent was evaporated on a hot plate $\left(60{ }^{\circ} \mathrm{C}\right)$ with a nitrogen gas jet (35-40 min). Air was removed with a syringe from the vials containing the dry residue, and vials were covered with parafilm and stored for $24 \mathrm{~h}$ at $-20^{\circ} \mathrm{C}$.

Prior to analysis by high performance liquid chromatography (HPLC), the residue was diluted in $0.7 \mathrm{~mL}$ of ethanol $15 \%$, following (Potrebko and Resurreccion 2009) protocol. The vial, protected by aluminum foil, was agitated manually for $30 \mathrm{~s}$, to loosen the extract completely from the wall, then subjected to ultrasound bath inside a plastic container, where it remained for $4 \mathrm{~min}$. The diluted extract was transferred to Eppendorf microtubes of $1.5 \mathrm{~mL}$ and centrifuged for $15 \mathrm{~min}$ at $25^{\circ} \mathrm{C}$ at $18,000 \mathrm{rpm}$. The supernatant of the centrifuged material was transferred to a $2 \mathrm{~mL}$ vial, protected from light and injected into HPLC.

As mobile phase, a gradient of acetonitrile and aqueous phosphoric acid $0.02 \%$ was used: acetonitrile $0 \mathrm{~min}, 13 \%$; 6-9 $\mathrm{min}, 15 \%$; $17 \mathrm{~min}, 17 \%$; 28-33 min, $28 \%$; $40 \mathrm{~min}, 50 \%$; $45 \mathrm{~min}, 60 \%$; 46-48 min, $80 \%, 49-54 \mathrm{~min} ; 13 \%$; flow 1.0 $\mathrm{mL} / \mathrm{min}$. The UV absorption was monitored at $308 \mathrm{~nm}, 280 \mathrm{~nm}$ and also at the length of maximum absorption (PDA). The injection volume was $10 \mu \mathrm{L}$. The resveratrol peak was identified by comparison of retention time with the standard, by the profile of the spectrum provided by PDA and co-eluting with the standard. Moreover, this compound was confirmed by comparison of chromatograms of induced and control samples, with a significant increase occurring at the 
peak in the retention time, corresponding to the resveratrol, after induction by UV. Resveratrol was quantified by the addition of phenolphthalein to the extracts and standards, as internal standard, according to (Potrebko and Resurreccion 2009).

Antioxidant activity

The antioxidant activity was evaluated by the DPPH (2, 2-diphenyl-1-picryl-hidrazila) method (Miliauskas et al. 2004). The methanol solution of DPPH $6 \times 10^{-5} \mathrm{M}$ was added to aliquots of the ethanol extract of leaves, the same used for resveratrol analysis, remaining in the dark for $60 \mathrm{~min}$. After reaction, the absorbance reading was performed in a Lambda 25 (Perkin Elmer ${ }^{\circledR}$, Beaconsfield, Bucks, UK) spectrophotometer at $515 \mathrm{~nm}$ using ethanol $80 \%$ as blank.

Data analysis

The mean expression of resveratrol was compared between the control and UV treatments by KruskalWallis test. Then, for the UV treatment, the effect of the three experimental blocks was evaluated for the expression of resveratrol. Once it had been detected that the average expression of resveratrol did not differ between the blocks, three blocks were joined and cluster analysis by unweighted pair group method with arithmetic mean (UPGMA) was applied to group species in accordance with their similarity in expression of resveratrol. Due to asymmetry of data, the genomes $\mathrm{A}, \mathrm{B}, \mathrm{AB}$ and $\mathrm{K}$ were compared for their mean expression by Kruskal-Wallis test $(\alpha<0.05)$. For data analysis, the program for statistical language $\mathrm{R}$ - version 2.13.2 was adopted, from a free download at the site http://www.r-project.org (R 2012).

\section{Results and discussion}

Most studies on chemical composition of wild Arachis species have focused on oil composition in seeds (Grosso et al. 2000; Wang et al. 2010). This is the first study on resveratrol in wild species of peanut.

We evaluated leaves of $\mathrm{A}, \mathrm{B}, \mathrm{AB}$ and $\mathrm{K}$ genome types species (Table 1) and in all of them resveratrol was detected (Table 2). Genome AB, represented by the allotetraploid A. hypogaea, had the highest content
Table 2 Resveratrol content $(\mu \mathrm{g} / \mathrm{g})$ in control and test samples of Arachis species

\begin{tabular}{|c|c|c|}
\hline \multirow[t]{2}{*}{ Species } & \multicolumn{2}{|l|}{ Treatment } \\
\hline & Control & UV \\
\hline A. batizocoi & Trace $^{\mathrm{a}}$ & $524.5 \pm 131.2^{\mathrm{b}}$ \\
\hline A. cardenasii & $29.8 \pm 5.2^{\mathrm{a}}$ & $733.3 \pm 135.7^{\mathrm{b}}$ \\
\hline A. cruziana & Trace $^{a}$ & $640.3 \pm 197.3^{b}$ \\
\hline A. duranensis & Trace $^{a}$ & $581.3 \pm 171.2^{\mathrm{b}}$ \\
\hline A. gregoryii & Trace $^{a}$ & $370.1 \pm 103.8^{b}$ \\
\hline A. ipaënsis & Trace $^{a}$ & $314.0 \pm 76.8^{\mathrm{b}}$ \\
\hline A. kempff-mercadoi & Trace $^{a}$ & $299.5 \pm 89.1^{\mathrm{b}}$ \\
\hline A. kuhlmannii & $35.4 \pm 26.8^{\mathrm{a}}$ & $802.3 \pm 180.2^{b}$ \\
\hline A. magna & $23.9 \pm 20.3^{\mathrm{a}}$ & $489.2 \pm 158.9^{\mathrm{b}}$ \\
\hline A. simpsonii & Trace $^{a}$ & $318.4 \pm 147.0^{\mathrm{b}}$ \\
\hline A. hypogaea & Trace $^{a}$ & $687.5 \pm 229.0^{\mathrm{b}}$ \\
\hline
\end{tabular}

Each result is mean of three blocks, each block evaluated in three repetitions; means followed by same letters in same line do not differ $(\alpha<0.05)$ according to Kruskal-Wallis test

Table 3 Average content of resveratrol $(\mu \mathrm{g} / \mathrm{g})$ per genome type evaluated

\begin{tabular}{ll}
\hline Genome & Mean \pm SD \\
\hline A & $565.1 \pm 291.9^{\mathrm{b}}$ \\
B & $394.2 \pm 136.7^{\mathrm{c}}$ \\
AB & $687.5 \pm 229.0^{\mathrm{a}}$ \\
K & $595.0 \pm 162.9^{\mathrm{b}}$ \\
\hline
\end{tabular}

Means followed by the same letters in the same column do not differ $(\alpha<0.05)$ according to the Kruskal-Wallis test

of resveratrol, $\mathrm{A}$ and $\mathrm{K}$ genomes had the second highest level of resveratrol content and $\mathrm{B}$ genome had the lowest (Table 3). A larger number of species and individuals per species have to be evaluated to be sure if there is any correlation between genome type and resveratrol content. However, some studies have shown higher levels of phenolic compounds in tetraploid individuals than in diploid individuals of some species (Lu et al. 2006; Sanwal et al. 2010; Caruso et al. 2011).

The resveratrol content of all species increased $(\alpha<0.05)$ in relation to the controls, i.e., compared to samples not submitted to UV light treatment (Table 2). Considering only the test induced samples, the concentrations of resveratrol ranged at $15 \mathrm{~h}$ after 
UV treatment from $299.5 \mu \mathrm{g} / \mathrm{g}$ in A. kempff-mercadoi to $819.9 \mu \mathrm{g} / \mathrm{g}$ in A. cardenasii (Table 1), with a mean of $516.9 \mu \mathrm{g} / \mathrm{g}$ in wild species.

The mean concentration of resveratrol in leaves of A. hypoagea $c v$ Caiapó was $687.5 \mu \mathrm{g} / \mathrm{g}$, which represented an average of 229-fold increase in resveratrol in relation to control (Fig. 1). Chung et al. (2003) and Tang et al. (2010) also observed an increase in resveratrol levels in leaves of 225 and 196 fold, respectively, after $2 \mathrm{~h}$ of UV exposure and $12 \mathrm{~h}$ of rest. The highest levels of resveratrol in A. hypogaea in this study may be due to the longer exposure time to $\mathrm{UV}$ light $(2 \mathrm{~h}$ and $30 \mathrm{~min}$ ) and rest time $(15 \mathrm{~h})$, combined with the fact that all leaflets had the same exposure to UV since detatched leaves were used instead of whole plants as in other studies (Chung et al. 2003; Tang et al. 2010). In stems of Vitis vinifera levels were found close to those seen in this study, at 6.0-490.0 $\mu \mathrm{g} / \mathrm{g}$ (Melzoch et al. 2001; Balík et al. 2008). Indeed, in roots of Polygonum cuspidatum, the main source of resveratrol, the levels are much higher, reaching 2,960.0-3,770.0 $\mu \mathrm{g} / \mathrm{g}$ (Vastano et al. 2000).

Our results showed that leaves are a suitable material to identify species that synthetize resveratrol. Since many studies on A. hypogaea have showed that resveratrol is present in leaves and also in many other tissues (seeds, roots, stalks, hypocotyls, cotyledons) we expect to find resveratrol in other tissues of the ten species in whose leaves we found resveratrol.

Peanut leaves are considered residues or by-products of peanut crops for the production of peanut oil or other purposes and, generally, are underutilized. However, the results obtained show that it is possible to add value to by-products (leaves) derived from the cultivation of peanuts, considering the various biological activities of resveratrol and its wide use in pharmaceuticals, cosmetics and food supplements.

Cluster methodology based on data of resveratrol content allowed the clustering of the species in three groups (Fig. 2 and Table 4). The first one comprised

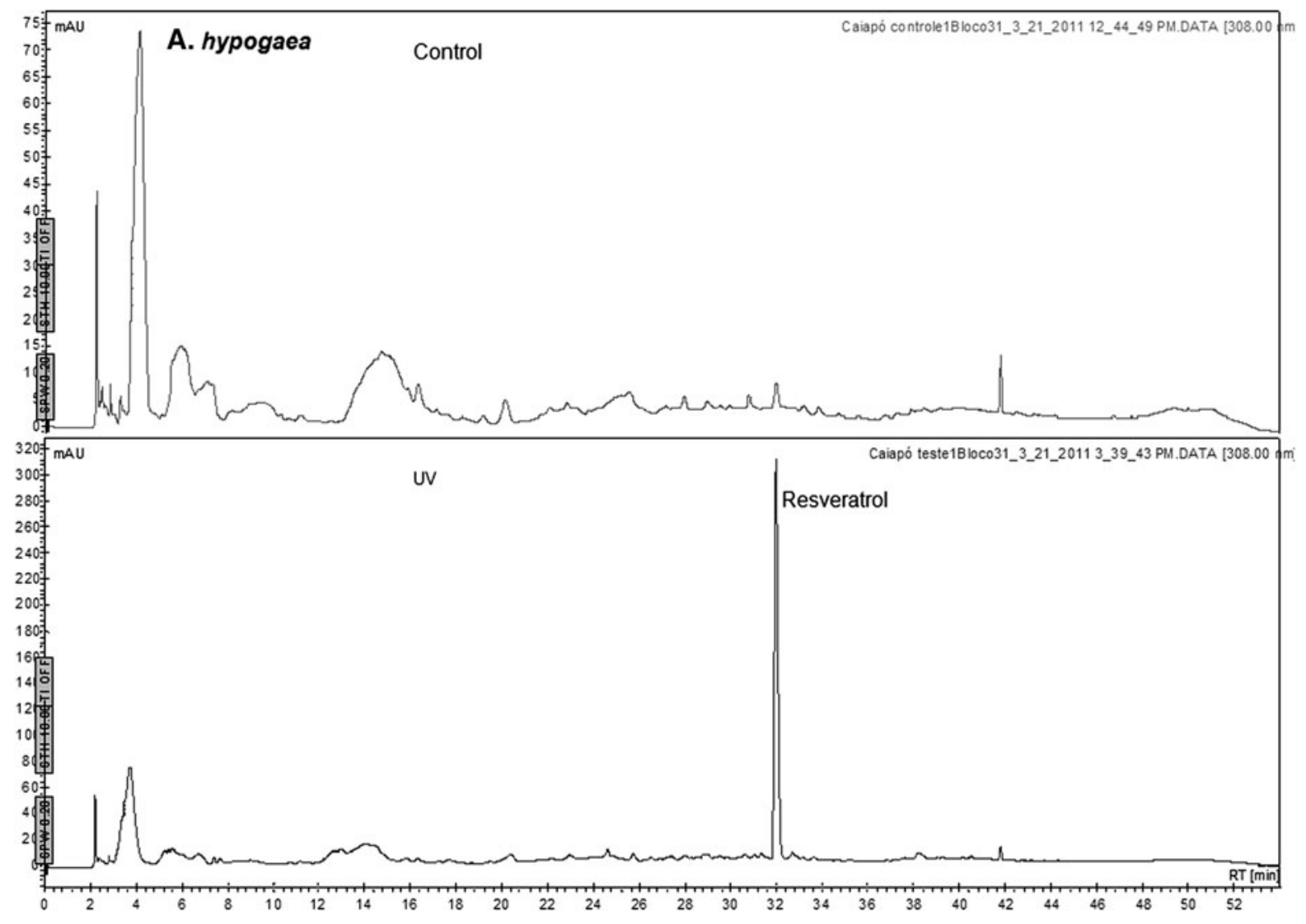

Fig. 1 Chromatograms obtained by HPLC of resveratrol ( $\mathrm{tR}=31.97 \mathrm{~min}$; purity $99.5 \%)$ in leaf extracts of A. hypogaea, control and induced treatments. Chromatographic conditions in the text 


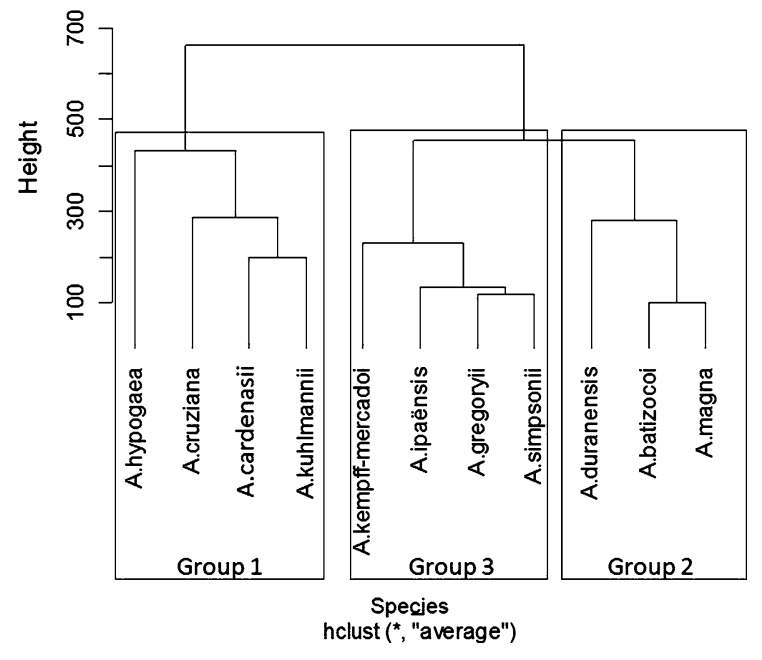

Fig. 2 Dendrogram based on resveratrol content showing the relationship between Arachis species. The three clusters observed included species that have different genomes. The first one comprised A. hypogaea (AB), A. cruziana (K), A. cardenasii (A) and A. kuhlmannii (A); the second cluster comprised A. kempff-mercadoi (A), A. ipaënsis (B), A. gregoryii (B) and A. simpsonii (A); and the third one A. duranensis, A. batizocoi and A. magna (B)

Table 4 Descriptive statistics for the cluster groups showing the similarity of Arachis species in relation to resveratrol expression $(\mu \mathrm{g} / \mathrm{g})$

\begin{tabular}{llll}
\hline Group & Mean \pm SD & Minimum & Maximum \\
\hline 1 & $801.9 \pm 130.7^{\mathrm{a}}$ & 596.0 & 973.0 \\
2 & $557.2 \pm 131.2^{\mathrm{b}}$ & 314.0 & 722.0 \\
3 & $323.9 \pm 93.3^{\mathrm{c}}$ & 198.0 & 500.0 \\
\hline
\end{tabular}

Means followed by the same letters in the same column do not differ $(\alpha<0.05)$ according to the Kruskal-Wallis test

A. cardenasii (A genome), A. cruziana (K genome), $A$. kuhlmannii (A genome) and A. hypogaea (AB Genome), species that had the highest resveratrol contents (Fig. 2 and Table 4). Arachis batizocoi (K genome), A. duranensis (A genome) and A. magna (B genome) were placed in a second group, and a third group was formed by A. gregoryii (B genome), A. kempff-mercadoi (A genome), A. simpsonii (A genome) and A. ipaënsis (B genome), which presented the lowest levels of resveratrol. The fact the groups comprised species that had different types of genomes, and previous phylogenetic data showed all A, B, D and $\mathrm{K}$ genomes species form a monophyletic group, with $\mathrm{B}, \mathrm{D}$ and $\mathrm{K}$ very closely related to each other (Bechara et al. 2010) suggest that the resveratrol synthase gene is present in all genome types ( $\mathrm{A}, \mathrm{B}, \mathrm{D}$ and $\mathrm{K}$ ) of section Arachis. Thus, our data suggest that in section Arachis we will find another 21 species that synthesize resveratrol, since this section comprises 32 species (Valls and Simpson 2005; Krapovickas and Gregory 2007) and in this study we have evaluated 10 of them and A. hypogaea.

Arachis ipaënsis, the donor of genome B to the cultivated species A hypogaea (Bechara et al. 2010; Grabiele et al. 2012), showed a very low mean value for resveratrol compared to other wild species. This species has only one accession available (KG 30076). However, phylogenetic studies showed that $A$. ipaënsis is closely related to A. magna, A. gregoryii, A. valida and $A$. williamsii (Cunha et al. 2008; Bechara et al. 2010); those species have many accessions available, and some of them may have high resveratrol content under stress. In fact, in this study the accession of $A$. magna evaluated was grouped with accessions with intermediary content of resveratrol (Fig. 2). This suggests that there is variability within the B genome group for resveratrol content and that it is possible to find $\mathrm{B}$ genome accessions that are able to synthesize higher amounts of resveratrol than A. ipaënsis.

The average content of resveratrol found in induced samples of A. hypogaea was $668.7 \mu \mathrm{g} / \mathrm{g}$. None of the wild species of Arachis studied presented a significantly higher concentration of resveratrol than $A$. hypogaea. However, previous studies on other plant species indicated the possibility of increasing phenylpropanoid derivatives, such as resveratrol, after polyploidyzation. Phenylpropanoid content was increased significantly in the wild potato Solanum commersonii Dun. after polyploidyzation (Caruso et al. 2011). Polyplodization also affected the level of expression of the phenylalanine ammonia-lyase gene (IiPAL), which increased significantly in tetraploid individuals of Isatis indigotica (Lu et al. 2006). Thus, the concentrations observed in A. cardenasii, $A$. cruziana and $A$. kuhlmannii can be considered high compared to peanut, because they are diploid species. Also, we have to take into account that in this study we compared data at just one time interval after UV induction, and the other species might have had higher resveratrol content before or after $15 \mathrm{~h}$ post-UV treatment, since they may have reacted differently to the stimulus because of the differences in leaf morphology observed between the species evaluated. 
The differences in leaf morphology between Arachis species have been used for species classification (Valls and Simpson 2005; Krapovickas and Gregory 2007).

The extracts of each species were also evaluated for antioxidant activity by DPPH method. The activity varied from $12.6 \%$ for A. duranensis to $44.7 \%$ for A. simpsonii in control samples and from $18.7 \%$ for A. duranensis to $60.7 \%$ in A. hypogaea. A significant increase in antioxidant activity was observed after induction by UV radiation in $A$. cardenasii, $A$. cruziana, A. hypogaea, A. kuhlmannii and A. batizocoi species (Table 5). Three of these species (except $A$. batizocoi) were also grouped with those that presented the highest content of resveratrol (Fig. 2), so it may be that the biosynthesis potential of this compound may have influenced the antioxidant potential of the species, evaluated by DPPH. The species A. batizocoi, which was grouped together with species showing medium capacity for resveratrol biosynthesis (Fig. 2), and A. cardenasii, also showed biosynthesis of other unidentified compounds, which may also have interfered in the antioxidant activity after induction by UV radiation. However, in general no correlation was observed between this antioxidant activity and resveratrol content found in different species evaluated. This lack of correlation can be explained by the low

Table 5 Mean \pm standard deviation of antioxidant activity (\%) evaluated in leaf extracts from different Arachis species by treatment

\begin{tabular}{lll}
\hline Species & \multicolumn{2}{l}{ Treatment } \\
\cline { 2 - 3 } & Control & $\mathrm{UV}$ \\
\hline A. batizocoi & $29.43 \pm 11.80^{\mathrm{a}}$ & $44.98 \pm 11.74^{\mathrm{b}}$ \\
A. cardenasii & $28.46 \pm 4.62^{\mathrm{a}}$ & $34.58 \pm 10.47^{\mathrm{b}}$ \\
A. cruziana & $30.45 \pm 9.50^{\mathrm{a}}$ & $35.61 \pm 12.16^{\mathrm{b}}$ \\
A. duranensis & $12.64 \pm 10.60^{\mathrm{a}}$ & $18.66 \pm 13.39^{\mathrm{a}}$ \\
A. gregoryii & $29.11 \pm 11.39^{\mathrm{a}}$ & $31.47 \pm 5.37^{\mathrm{a}}$ \\
A. ipaënsis & $38.02 \pm 13.77^{\mathrm{a}}$ & $36.34 \pm 9.24^{\mathrm{a}}$ \\
A. kempff-mercadoi & $29.58 \pm 14.85^{\mathrm{a}}$ & $29.10 \pm 15.04^{\mathrm{a}}$ \\
A. kuhlmannii & $13.28 \pm 5.00^{\mathrm{a}}$ & $19.61 \pm 4.92^{\mathrm{b}}$ \\
A. magna & $24.69 \pm 11.44^{\mathrm{a}}$ & $24.79 \pm 6.27^{\mathrm{a}}$ \\
A. simpsonii & $44.75 \pm 29.94^{\mathrm{a}}$ & $48.16 \pm 33.38^{\mathrm{a}}$ \\
A. hypogaea & $44.63 \pm 22.90^{\mathrm{a}}$ & $60.69 \pm 15.23^{\mathrm{b}}$ \\
\hline
\end{tabular}

Lines with the same letters indicate that treatments do not differ, according to the generalized linear models, assigning Gamma distribution to antioxidant expression $(\alpha<0.05)$ reactivity of resveratrol with the DPPH, as shown by Sanchez-Moreno et al. (1998).

In conclusion, the results showed that all wild species of Arachis evaluated in this study have potential for production of resveratrol after induction by UV radiation. The results showed that wild Arachis species are a potential source of alleles for improvement of cultivated peanut, if aiming to achieve high contents of resveratrol. Species of genome A and genome $\mathrm{B}$ with higher levels of resveratrol could be used to obtain synthetic amphidiploids, which could also be used in production of resveratrol or crossed with A. hypogaea to increase the level of production of this compound in cultivated peanut.

Acknowledgments We thank Dr. Alessandra Fávero, José F.M. Valls, Marcio Moretzsohn and Soraya Leal-Bertioli for providing the seeds of wild species and Antonieta N. Salomão for germination of seeds.

\section{References}

Arora MK, Strange RN (1991) Phytoalexin accumulation in groundnuts in response to wounding. Plant Sci 78(2):157-163. doi:10.1016/0168-9452(91)90194-D

Balík J, Kyseláková M, Vrchotová N, Tříska J, Kumšta M, Veverka J, Híc P, Totušek J, Lefnerová D (2008) Relations between polyphenols content and antioxidant activity in vine grapes and leaves. Czech J Food Sci 26:S25-S32 (Special Issue)

Bechara MD, Moretzsohn MC, Palmieri DA, Monteiro JP, Bacci M Jr, Martins J Jr, Valls JF, Lopes CR, Gimenes MA (2010) Phylogenetic relationships in genus Arachis based on ITS and 5.8S rDNA sequences. BMC Plant Biol 10:255. doi:10.1186/1471-2229-10-255

Brito AR (1996) How to study the pharmacology of medicinal plants in underdeveloped countries. J Ethnopharmacol 54(2-3):131-138. doi:10.1016/S0378-8741(96)01460-2

Caruso I, Lepore L, De Tommasi N, Dal Piaz F, Frusciante L, Aversano R, Garramone R, Carputo D (2011) Secondary metabolite profile in induced tetraploids of wild Solanum commersonii Dun. Chem Biodivers 8(12):2226-2237. doi: 10.1002/cbdv.201100038

Chen RS, Wu PL, Chiou RYY (2002) Peanut roots as a source of resveratrol. J Agric Food Chem 50(6):1665-1667. doi: 10.1021/Jf011134e

Chukwumah Y, Walker L, Vogler B, Verghese M (2012) Profiling of bioactive compounds in cultivars of runner and Valencia peanut market-types using liquid chromatography/APCI mass spectrometry. Food Chem 132(1):525531. doi:10.1016/j.foodchem.2011.10.050

Chung I-M, Park MR, Chun JC, Yun SJ (2003) Resveratrol accumulation and resveratrol synthase gene expression in response to abiotic stresses and hormones in peanut plants. Plant Sci 164(1):103-109. doi:10.1016/s0168-9452(02) 00341-2 
Cunha F, Nobile P, Hoshino A, Moretzsohn M, Lopes C, Gimenes M (2008) Genetic relationships among Arachis hypogaea L. (AABB) and diploid Arachis species with AA and BB genomes. Genet Resour Crop Evol 55(1):15-20. doi:10.1007/s10722-007-9209-6

Favero AP, Simpson CE, Valls JFM, Vello NA (2006) Study of the evolution of cultivated peanut through crossability studies among Arachis ipaensis, A.duranensis, and A.hypogaea. Crop Sci 46(4):1546-1552. doi:10.2135/ cropsci2005.09-0331

Fritzemeier K-H, Rolfs C-H, Pfau J, Kindl H (1983) Action of ultraviolet-C on stilbene formation in callus of Arachis hypogaea. Planta 159(1):25-29. doi:10.1007/bf00998810

Fulda S (2010) Resveratrol and derivatives for the prevention and treatment of cancer. Drug Discov Today 15(17-18):757-765. doi:10.1016/j.drudis.2010.07.005

Grabiele M, Chalup L, Robledo G, Seijo G (2012) Genetic and geographic origin of domesticated peanut as evidenced by 5S rDNA and chloroplast DNA sequences. Plant Syst Evol 298(6):1151-1165. doi:10.1007/s00606-012-0627-3

Grosso NR, Nepote V, Guzman CA (2000) Chemical composition of some wild peanut species (Arachis L.) seeds. J Agric Food Chem 48(3):806-809. doi:10.1021/jf9901744

Harikumar KB, Aggarwal BB (2008) Resveratrol-A multitargeted agent for age-associated chronic diseases. Cell Cycle 7(8):1020-1035. doi:10.4161/cc.7.8.5740

Ingham JL (1976) 3, 5, 4'-Trihydroxystilbene as a phytoalexin from groundnuts (Arachis hypogaea). Phytochemistry 15(11):1791-1793. doi:10.1016/s0031-9422(00)97494-6

Krapovickas A, Gregory WC (2007) Taxonomy of the genus Arachis (Leguminosae). Bonplandia 16:1-205 (Supl.)

Lopes RM, Agostini-Costa TS, Gimenes MA, Silveira D (2011) Chemical composition and biological activities of Arachis species. J Agric Food Chem 59(9):4321-4330. doi: $10.1021 / \mathrm{jf} 104663 \mathrm{z}$

Lu B-B, Du Z, Ding R-X, Zhang L, Yu X-J, Li C-H, Chen W-S (2006) Cloning and characterization of a differentially expressed phenylalanine ammonialyase gene (liPAL) after genome duplication from tetraploid Isatis indigotica Fort. J Integr Plant Biol 48(12):1439-1449. doi:10.1111/j.16729072.2006.00363.x

Mallikarjuna N, Senthilvel S, Hoisington D (2011) Development of new sources of tetraploid Arachis to broaden the genetic base of cultivated groundnut (Arachis hypogaea L.). Genet Resour Crop Evol 58(6):889-907. doi:10.1007/ s10722-010-9627-8

Melzoch K, Hanzlíková I, Filip V, Buckiová D, Šmidrkal J (2001) Resveratrol in parts of vine and wine originating from Bohemian and Moravian vineyard regions. Agriculturae Conspectus Scientificus 66(1):53-57

Miliauskas G, Venskutonis PR, van Beek TA (2004) Screening of radical scavenging activity of some medicinal and aromatic plant extracts. Food Chem 85(2):231-237. doi: 10.1016/j.foodchem.2003.05.007

Moretzsohn MC, Leoi L, Proite K, Guimaraes PM, Leal-Bertioli SC, Gimenes MA, Martins WS, Valls JF, Grattapaglia D, Bertioli DJ (2005) A microsatellite-based, gene-rich linkage map for the AA genome of Arachis (Fabaceae). Theor Appl Genet 111(6):1060-1071. doi:10.1007/s00122-005-0028-x

Moretzsohn MC, Barbosa AV, Alves-Freitas DM, Teixeira C, Leal-Bertioli SC, Guimaraes PM, Pereira RW, Lopes CR,
Cavallari MM, Valls JF, Bertioli DJ, Gimenes MA (2009) A linkage map for the B-genome of Arachis (Fabaceae) and its synteny to the A-genome. BMC Plant Biol 9:40. doi: 10.1186/1471-2229-9-40

Nielen S, Vidigal BS, Leal-Bertioli SC, Ratnaparkhe M, Paterson AH, Garsmeur O, D'Hont A, Guimaraes PM, Bertioli DJ (2012) Matita, a new retroelement from peanut: characterization and evolutionary context in the light of the Arachis A-B genome divergence. Mol Genet Genomics 287(1):21-38. doi:10.1007/s00438-011-0656-6

Potrebko I, Resurreccion AV (2009) Effect of ultraviolet doses in combined ultraviolet-ultrasound treatments on trans-resveratrol and trans-piceid contents in sliced peanut kernels. J Agric Food Chem 57(17):7750-7756. doi:10.1021/jf900 $667 \mathrm{~d}$

R (2012) R-2.13.2. http://www.r-project.org. Accessed 25 July 2012

Rates SM (2001) Plants as source of drugs. Toxicon off J Int Soc Toxinol 39(5):603-613

Sanchez-Moreno C, Larrauri JA, Saura-Calixto F (1998) A procedure to measure the antiradical efficiency of polyphenols. J Sci Food Agric 76(2):270-276. doi:10.1002/ (sici)1097-0010(199802)76:2<270:aid-jsfa945>3.0.co;2-9

Sanders TH, McMichael RW Jr, Hendrix KW (2000) Occurrence of resveratrol in edible peanuts. J Agric Food Chem 48(4):1243-1246

Sanwal SK, Rai N, Singh J, Buragohain J (2010) Antioxidant phytochemicals and gingerol content in diploid and tetraploid clones of ginger (Zingiber officinale Roscoe). Sci Hortic 124(2):280-285. doi:10.1016/j.scienta.2010.01.003

Sobolev VS, Cole RJ (1999) Trans-resveratrol content in commercial peanuts and peanut products. J Agric Food Chem 47(4):1435-1439. doi:10.1021/jf9809885

Tang K, Zhan J-C, Yang H-R, Huang W-D (2010) Changes of resveratrol and antioxidant enzymes during UV-induced plant defense response in peanut seedlings. J Plant Physiol 167(2):95-102. doi:10.1016/j.jplph.2009.07.011

Tokusoglu O, Unal MK, Yemis F (2005) Determination of the phytoalexin resveratrol (3,5,4'-trihydroxystilbene) in peanuts and pistachios by high-performance liquid chromatographic diode array (HPLC-DAD) and gas chromatography-mass Spectrometry (GC-MS). J Agric Food Chem 53(12):5003-5009. doi:10.1021/jf050496+

Valls J, Simpson C (2005) New species of Arachis L. (Leguminosae) from Brazil, Paraguay and Bolivia. Bonplandia 14:35-64

Vastano BC, Chen Y, Zhu N, Ho CT, Zhou Z, Rosen RT (2000) Isolation and identification of stilbenes in two varieties of Polygonum cuspidatum. J Agric Food Chem 48(2): 253-256

Wang ML, Barkley NA, Chinnan M, Stalker HT, Pittman RN (2010) Oil content and fatty acid composition variability in wild peanut species. Plant Genet Resour Charact Util 8(3):232-234. doi:10.1017/s1479262110000274

Yang M-H, Lin Y-J, Kuo C-H, Ku K-L (2010) Medicinal mushroom ganoderma lucidum as a potent elicitor in production of t-resveratrol and t-piceatannol in peanut calluses. J Agric Food Chem 58(17):9518-9522. doi:10.1021/ jf102107p 